\title{
11 Government accounting in the Global South: the design, implementation and use of global solutions for local needs
}

\author{
Andy Wynne and Stewart Lawrence
}

\section{INTRODUCTION}

This chapter examines the impact of globalized accounting and economic reforms on the public sectors of the Global South, focusing particularly on the countries in Sub-Saharan Africa. Over the last three decades, people living in these countries have experienced debt crises, civil wars, coups and, on top of all that, externally imposed neoliberal economic reforms. Accounting has been an integral part of those imposed 'reforms'.

International creditor institutions and donor agencies have promoted new public management (NPM) reforms in all developing countries (Ayeni, 2002). The central features of NPM have been said to include: a shift in emphasis from process accountability (input controls and bureaucratic procedures, rules and standards) to accountability for results (quantifiable outcomes, measures and performance targets); and devolution of management control, coupled with the development of improved reporting, monitoring and accountability mechanisms (Awio, Lawrence and Northcott, 2007). The claimed benefits of such reforms include improvements in efficiency, effectiveness and accountability of the public sector. Universally, the reforms were expected to engender greater public service responsiveness and increased choice of providers of services, private as well as public (Olson, Guthrie and Humphrey, 1998). However, we argue that the results indicate that the global reforms have not necessarily met the needs of the local populations who have had to endure them.

After stripping away activities that could be privatized, the remaining core government services were the targets of better financial management. Two of the most frequently recommended tools of public financial management for developing countries are the medium-term expenditure framework (MTEF) and integrated financial management information systems (IFMIS). We examine the design, implementation and use of these global remedies, whose introduction we argue was based on theoretical assumptions as opposed to experience of their effects. We note the growing concern that is being expressed about the effectiveness of such interventions.

We illustrate that the reforms in accounting procedures in central government have been less successful than anticipated. The use of expensive external consultants at the expense of local experts is discussed. We conclude with some lessons for a way forward, suggesting greater reliance be placed on local expertise, which needs to be nourished.

Before solutions can be assessed we have to understand the problem and how it arose. For this reason, this chapter provides some background on the financial plight of the governments in the Global South, and argues that there may be a widespread misconception about the causal nature of their predicaments. Typically it is assumed 
that the poverty and lack of economic growth in these countries were the result of the poor administration and public financial practices. In our view, the causal direction may have been in the opposite direction. It is argued below that it was economic decline and poverty that caused poor administration and financial management and encouraged corruption. If this was indeed the case, the use of foreign consultants to introduce large-scale 'modern' reforms may have accentuated the problem. This approach may have further undermined the confidence of local managers and so reduced their ability to ensure that the local environment was fully considered. We argue that the reforms needed the full involvement of local public financial managers in the rebuilding of their systems and institutions, ensuring that the reforms had a good fit with associated systems and were fully owned and understood by local officials. The involvement of local officials is particularly important with accounting reforms, where the information produced has to be fully appreciated if it is to be used effectively.

\section{BACKGROUND TO THE LARGE LEVELS OF DEBT}

The argument in this section is that the causal relationship runs contrary to the conventional view. Economic problems (originating from external events) led to the deterioration in the quality of governance and public financial management in many African countries. The international financial institutions and bilateral aid agencies used the crises to introduce wide-ranging public sector financial management reforms, for example the MTEF and IFMIS. They also unsuccessfully argued for the adoption of international public sector accounting standards and performance audit.

\subsection{The Origins of the Global South's Debt Burden}

In the first few years after independence the economies of many African countries grew significantly and so their governments could afford to expand public services dramatically, especially for health and education. With the first major oil price rises in 1973-74, funds were readily available for these countries to borrow for significant public investment programmes.

Not surprisingly, then, many countries concentrated on Big Projects - showpiece government development projects that could be the motor for economic transformation, such as Ghana's Volta River Project, which involved construction of the Akosombo Dam in the early 1960s to form the world's largest artificial lake and building aluminium smelters to take advantage of the country's bauxite resources. (Situmbeko and Zulu, 2004, p. 16)

The experience of the US and UK in the years following the Second World War had shown that extensive government borrowing could facilitate economic growth. In the US the federal debt alone (excluding state or local government debt) reached over 120 per cent of GDP in 1946 (Office of Management and Budget, 2007) and in the UK government debt peaked at nearly 250 per cent of GDP (Clark and Dilnot, 2002) at around the same time. The sustained economic boom of the 1950 s and 1960 s meant that these levels of debt were sustainable, could be accommodated and were eventually repaid. In addition, inflation did not reach double figures in the UK until the mid-1970s. 
However, most governments of the Global South were not so lucky. In 1979-80 further oil price rises increased the price of their imports. Around the same time, in the late 1970 s and early 1980 s the United States raised interest rates to nearly 20 per cent in a battle to throttle back its persistent inflation (Stiglitz, 2006). The real (inflation-adjusted) interest rates paid by the Global South increased from -4 per cent in 1975 to almost +4 per cent a decade later (Bond, 2006).

A strategy for development, based on indebtedness ... was suddenly transformed into an actual catastrophe by a decision emanating from a fraction of ruling classes within leading capitalist countries, with a total indifference for the hardship imposed on the third world (as well as for the rise of unemployment everywhere). (Duménil and Lévy, 2005)

The rapid increase in world interest rates in the early 1980s on top of the oil price rises led to a world recession. As a result most countries in the Global South faced a reduced demand for their exports whilst having to pay much higher interest rates on their debts. As Christian Aid (2003, p. 22) reported:

the prices Third World countries receive for many of their traditional exports, from coffee and cocoa to rice, sugar, and cotton, continue to decline. The relative value of their exports has declined even more - for example, in 1975 a new tractor cost the equivalent of 8 metric tons of African coffee, but by 1990 the same tractor cost 40 metric tons.

The United Nations Food and Agriculture Organization (FAO, 2005) estimated that, if commodity prices had maintained the same real value as in 1980 , the Global South would be earning an additional $\$ 112$ billion in annual export revenues, which was double the then level of their aid receipts. Putting it another way, between 1970 and 1997 changes in the terms of trade cost non-oil-producing African states (excluding South Africa) a total of 119 per cent of their annual GDP, according to the World Bank (2000). External debt grew by 106 per cent of GDP over the same period. So all the external debt of African countries at the end of the twentieth century could be explained by falling prices for their exports and increasing prices of imports - both changes over which their governments had little or no control.

As UNCTAD (2004, p. 5) describes the result:

From just over $\$ 11$ billion in 1970, Africa had accumulated over $\$ 120$ billion of external debt in the midst of the external shocks of the early 1980s. Total external debt then worsened significantly during the period of structural adjustment in the 1980s and early 1990s, reaching a peak of about $\$ 340$ billion in 1995.

In the same report UNCTAD calculates that between 1970 and 2002 Sub-Saharan Africa received $\$ 294$ billion in loans, and paid back $\$ 268$ billion in debt service, but was left with debts of some $\$ 210$ billion (2004, p. 9 ).

Africa now repays more than it receives. In 1980, loan inflows of $\$ 9.6$ billion were comfortably higher than the debt repayment outflow of $\$ 3.2$ billion ... by 2000 , only $\$ 3.2$ billion flowed in, and $\$ 9.8$ billion was repaid, leaving a net financial flows deficit of $\$ 6.2$ billion . . . By the early 2000 s, the debt remained unbearable for at least 21 African countries at more than 300 per cent of export earnings. (Bond, 2006, p. 39) 
The solution to the indebtedness envisioned by the World Bank and other international development agencies was the introduction of NPM reforms in all developing countries. The claimed benefits of such reforms included improvements in efficiency, effectiveness and accountability of the public sector.

\section{NEED FOR AND DESIGN OF 'MODERN' FINANCIAL MANAGEMENT SYSTEMS}

The high and unsustainable levels of debt in many developing countries were thus due to external economic events beyond the control of their governments. However, whatever its origin, this debt forced governments to approach the IMF and the World Bank for support. The debt burden gave the World Bank and IMF the leverage needed to implement policies of deregulation and privatization through structural adjustment programmes. These almost invariably included the following elements:

- reduced government spending and greater fiscal discipline to control inflation;

- removing import controls and restrictions on capital movements;

- privatization of state enterprises;

- devaluation of the currency;

- making labour more flexible by reducing legal protection, food subsidies and minimum wages.

As Colin Leys described, the dominant view became that:

Governments were part of the problem, not part of the solution; they were inefficient and often corrupt and hence parasitic, not stimulators of growth. The solution was to privatize the public sector, reduce the scale and scope of government spending and give up all policies, from exchange rate controls to subsidies and redistributive taxation, that altered any prices that would otherwise be set by the impersonal forces of the market. (Leys, 1996, p. 18)

As well as greater fiscal discipline, privatization of previously state-run organizations, in industries such as telecommunications, postal services, shipping, forestry and water supplies, was encouraged.

After stripping away activities that could be privatized, the remaining core government services were the targets of better financial management. Modern tools of public financial management were imported to governments of the Global South. These tools were the MTEF and IFMIS. We will examine the design rationality and claims made for each of these techniques, then their implementation using overseas consultants, and finally their limitations and outcomes.

Although MTEFs differ across countries, broadly defined the MTEF approach is a means for linking policy, planning and budgeting. The time horizon for government budgeting was to be extended from the traditional annual budget to the medium term, usually three years. Simultaneously, budgetary control was to move from agreeing resource inputs to providing the resources necessary for agreed outputs and, ideally, outcomes. An MTEF consists of a 'top-down resource envelope, a bottom-up estimation 
of the current and medium-term costs of existing policy and, ultimately, the matching of these costs with available resources' (World Bank, 1998, p.48). The aim of the system was that government ministries would have increased predictability of resource flows over the next few years, and improved accountability and transparency for the level of services they provided in addition to the resources they consumed, and that this would ultimately lead to a more effective and efficient process of resource allocation towards strategic priorities within and between sectors.

The generic objectives of an MTEF are generally considered to be:

- facilitating the achievement of a balanced budget (fiscal discipline);

- enabling the shift of resources to pro-poor areas of the budget in line with agreed poverty reduction strategies.

Another major reform which the World Bank and other donors have heavily promoted across the public sectors of the Global South is the concept of an IFMIS. This is a computerized system designed to support public expenditure management goals and priorities across the whole of government. An IFMIS 'usually refers to computerization of public expenditure management processes, including budget formulation, budget execution, and accounting, with the help of a fully integrated system for financial management of the line ministries and other spending agencies' (Diamond and Khemani, 2005, p. 3).

By tracking financial events through automated financial operations, governments are expected to be able to control expenditure better and improve transparency and accountability in the budget cycle as a whole. While definitions of the key components of an IFMIS vary, proponents argue that this technology provides a set of tools that assist government in undertaking the following tasks:

- designing appropriate fiscal and monetary responses to changing macroeconomic conditions;

- ensuring accountability for the deployment and use of public resources;

- improving the effectiveness and efficiency of public expenditure programmes;

- mobilizing domestic resources and managing external resources (foreign aid and loans);

- managing civil services; and

- decentralizing operations with adequate controls.

The aim of an IFMIS is to integrate all aspects of the government's budgetary cycle and provide suitable interfaces to other systems and entities. Thus an IFMIS may be based on the generic model shown in Figure 11.1.

An integrated treasury system offers several significant benefits in managing public monies more effectively:

- Full integration of budget and budget execution data, thereby allowing greater financial control;

- Improved planning for cash as well as close and timely monitoring of the government's cash position;

- Provision of adequate management reporting at various levels of budget execution; 


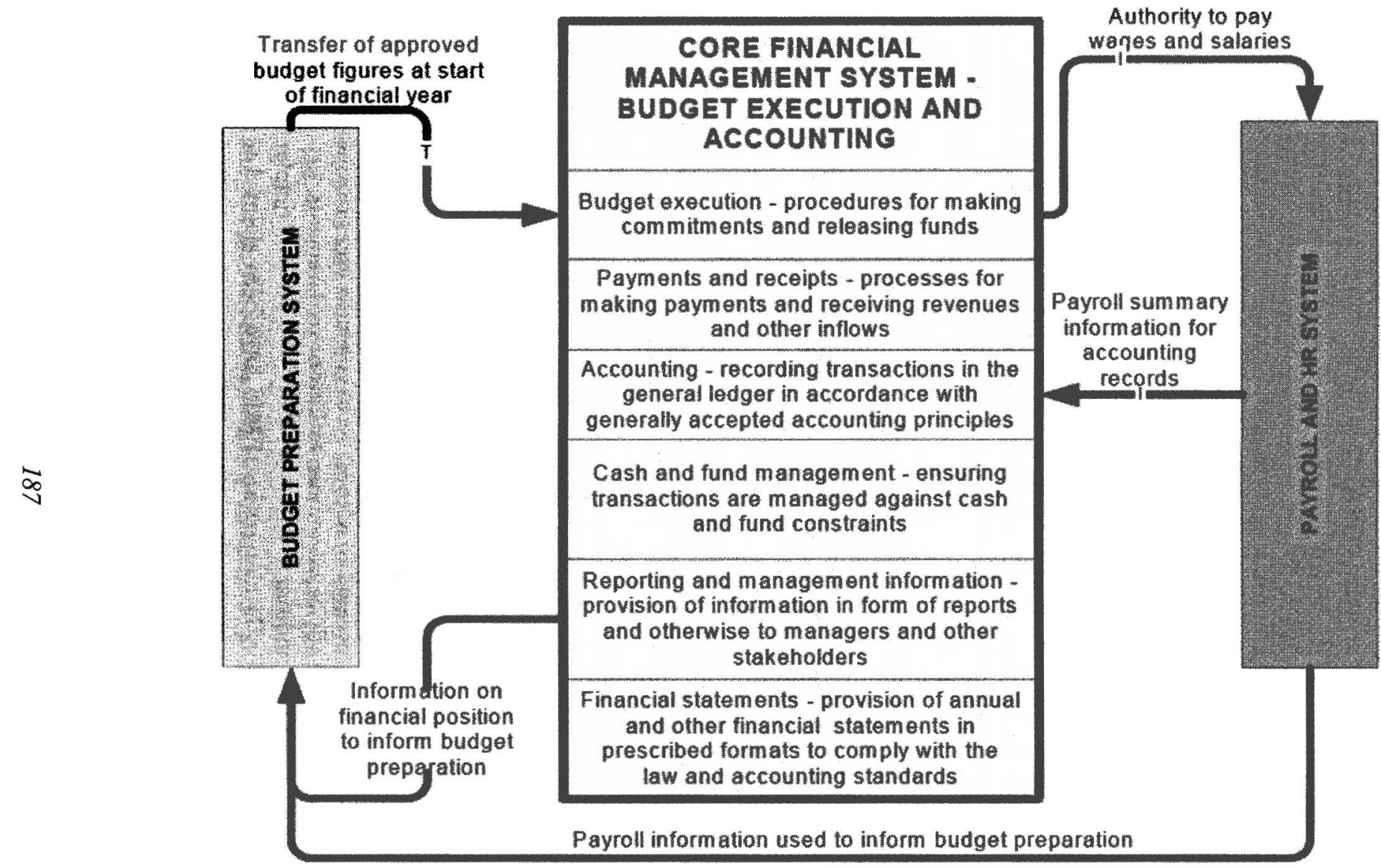

Source: Mike Parry, IMCL, www.imcl.co.uk.

Figure 11.1 Overview of IFMIS component interfaces 
- Improvement of data quality for the preparation and execution of the budget; and

- Facilitation of the preparation of financial statements and other financial reports for budgeting, analysis and financial control. (Hashim and Allan, 2001)

The hope of reformers was that the MTEF and IFMIS technologies would support the modernization of public financial management and the introduction of good governance. However, as considered in the following sections, the necessary preconditions for these complex reforms were not necessarily available, and the use of foreign consultants accentuated the problem of a lack of local capacity.

\section{IMPLEMENTATION - AND THE (MISSING) NECESSARY PRECONDITIONS}

The successful introduction of these new technologies is dependent upon certain preconditions. These preconditions were not generally in place in the public sectors of the Global South. In addition to the traditional requirement of budget discipline, the following technical and institutional factors are considered essential for a successful MTEF:

- a clear framework of national objectives and policies, and sector objectives and strategies

- realistic medium-term resource projections that ensures predictable flows of programmed resources to implementing agencies

- a comprehensive budget that captures all the expenditures by the government as well as on behalf of the government, for instance by donors and NGOs

- an integrated budget that enables the budget system to relate results and accountabilities to resource inputs

- a budget and program classification that can be linked to the national and sectoral objectives, that is a functional classification and facilitates the integration of the budget

- financial management institutions to ensure transparency and accountability in the use of budget resources

- monitorable indicators of inputs, final and intermediate outputs and outcomes, quantitative and qualitative targets of these indicators and a system for regular monitoring of the progress toward meeting the targets. The monitoring provides the basis to assess results and accountabilities and make adjustments in objectives, targets and budget allocations. (World Bank, 2005, p. 8)

Two questions over the implementation of the MTEF are the extent to which objectives have been formally agreed for the country concerned, and whether these have been agreed by all the major stakeholders. Questions may also be raised about whether these objectives were internally generated to address local concerns and priorities or whether they were based on external advice, recommendations or requirements.

Similarly there are preconditions necessary for the successful implementation of an IFMIS. Preconditions for developing an IFMIS have been claimed to include the following: 
- Authorities' commitment and ownership is clear

Clear institutional designation

Clear authority to implement

Active involvement, with no undue delegation to suppliers

- Preconditions are ready for reform

Authorities prepared to reengineer work practices

Environment encourages reform

Sufficient skills and/or training available

Users are 'sold' on the system

Steering group is active and representative

- Project design is sound

Adequate time taken on design phase

Users fully involved in specification

Not too ambitious in scope

Timetable is realistic

- Management of project is capable

Adequate management skills

Managers motivated to reform

Full-time implementation team identified

In-house or outsourced maintenance capacity identified, in place, and properly costed

- Adequate resources are assured

Sufficient funds since actual costs might exceed anticipated cost

Resource demands caused by operating two parallel systems simultaneously

Sufficient resources for long-term operation and maintenance of the system

(Diamond and Khemani, 2005)

\subsection{Implementation Issues: Consultants and Expertise}

Private sector international consultants have been called upon widely to assist with the implementation of IFMIS, MTEF and other major public financial management reforms in the Global South. The nature of these reforms means that knowledge and experience are not available locally. So, for example, almost invariably, IFMIS projects will be unique in the country concerned, at least in the public sector. Thus the use of international consultants will usually be considered essential.

However, the success of such large-scale reforms is also dependent upon a detailed understanding of the local environment, existing systems and institutions. This is only available from local public financial management officials. As a result, to be successful, such reforms require close co-operation, understanding and mutual respect between these two sets of experts, the local officials and international consultants.

However, the consultancy firms are usually major companies, and so the relationship between the client government officials and the consultants is not a relationship between equals. The budgets of consultancy firms, for example, often outstrip those of 
the countries in which they work. PricewaterhouseCoopers, for example, recorded a total revenue of US\$26.2 billion for its 2009 financial year- a figure that far outstrips the GDP of any country in Sub-Saharan Africa with the exception of Nigeria and South Africa (www.pwc.com). In addition, the international consultancy firms have access to more information about actual successes and challenges that other governments have experienced with their MTEF and IFMIS reforms (they may also have relationships with suppliers of IT equipment or software).

As a result, the local knowledge, experience and detailed appreciation of the local government officials are not necessarily used effectively. Capacity development is often a key dimension of such large-scale projects. However, the use of international experts may have the effect of further demoralizing local officials, undermining their self-confidence and so actually reducing their capacity. As a result some research has highlighted the risk of dependency on consultants; for example, Fyson (2009), based on research into the introduction of an IFMIS in Ghana, outlined the dilemma as follows:

Some of the literature focuses on the work of contractors as a necessary contribution to the development effort bringing both resources and expertise to assist in building local capacity ... In contrast, other scholars, have argued that the work of consultants funded by development agencies, almost by definition, will have a nefarious impact on the longer-term prospects for development (Berg 1993, Reality of Aid 1999, Easterly 2002). After all, how can private sector consultants earning many times their counterpart's salary assist the public sectors of low income and aid dependent countries (Wedel 1998, Jones 1997)? Instead expatriate consultants and advisors are perceived as a systematic destructive force which is undermining the development of capacity in Africa.

In the UK, private sector consultants are also used extensively to advise public sector officials, but the relationship between the two partners is far more equal. Despite this, the National Audit Office (UK, 2006) identified the following recommendations to ensure the more effective use of consultants:

1. Public bodies need to be much better at identifying where core skill gaps exist in relation to medium- and long-term programme requirements. This knowledge should be used to plan for recruitment, training, and using consultants. Recruitment of fulltime personnel and training of existing personnel can provide better value for money than continued use of consultants.

2. Public bodies should start with the presumption that their own staff are best fitted for their requirements. While it will often be the case that they need to purchase specific expertise from consulting firms, more generalist requirements can be met more cost-effectively by internal resources.

3. Public bodies should adhere to agreed regulations on the recommended threshold levels requiring ministerial or permanent secretary approval of consultancy contracts. Approvals should be based on a robust business case. Adhering to the guidance will ensure that senior management has full sight of the larger consulting contracts, promoting better accountability for this spend.

4. Public bodies need to engage with the market earlier to explore a range of possible approaches and contracting methods. Early contact with suppliers during the procurement process improves both the supplier's and the client's understanding of the 
requirement. Public bodies would get more tailored and innovative responses to their invitations to tender.

5. Public bodies should make more use of different payment mechanisms such as fixed price and incentivized contracts instead of the standard time and materials. Different payment mechanisms can help control costs and formalize the joint objectives between clients and consultants. The different payment options require a strong understanding of the project's objectives, scope, risks and approach.

6. Public bodies must be smarter when it comes to understanding how consulting firms operate and in sharing information about their performance. Public bodies should have regular, senior-level discussions with their consultants to discuss openly medium- to long-term objectives and plans. Public bodies should also use their understanding of suppliers' objectives to maximize their purchasing advantage. Public bodies need to have a clear understanding of who their key suppliers are, how they are organized, their incentive mechanisms (which might focus on selling further work), and commercial practices.

7. Public bodies need to provide sufficient incentive to staff to make the consultancy project a success. Recent research has shown that the further removed people are from the decision to use consultants the more likely they are to feel confused about project responsibilities and accountabilities and frustrated because they don't know what the consultants are doing, to complain of poor communication and to be cynical about the consultants' involvement.

\subsection{Lack of Local Capability: Worsening Pay and Conditions for Public Sector Workers}

The use of expensive external consultants has to be understood in the context of what was happening to the economies and working conditions of local populations. The general deterioration in the economic conditions across the Global South led to a significant reduction in the real pay of public sector workers and so had a detrimental effect on the quality of public financial management across much of the Global South. Their public sectors were downsized and wage levels deteriorated significantly, leading to problems of loss of skills and capacity.

Efficient, accountable, adequately paid and well-motivated civil servants are essential for an effective public sector, and especially to implement relatively complex reforms such as an MTEF or an IFMIS. Civil service reform was a major component of structural adjustment lending in the 1980s and the 1990s. Yet for the World Bank and IMF, such reforms primarily meant reducing the size of the civil service. At the same time, structural adjustment programmes led to a large decline in wages for civil servants who remained (Hawley, 2000).

The IMF, for example, prompted wage reductions averaging 14 per cent in 20 African countries in the 1990s (Lienert and Modi, 1997: 18). The use of outside experts, funded by technical assistance loans, may also have hampered the growth of local expertise and capacity (Rama, 1997: 2) and demoralized the existing local professional staff, thereby adversely affecting their ability to successfully implement such complex reforms. (Wynne, 2005, pp. 31-2)

Real wages in nearly every African country were estimated to have fallen between 50 and 60 per cent since the imposition of the structural adjustment programmes of the $1980 \mathrm{~s}$ (ILO/JASPA, 1991). 
By 1990 Margaret Joan Anstee, the UN under-secretary-general, could warn that:

The impact of recession and adjustment in the 1980s has been dealt with by economists and policy makers, within a framework of macro-analysis that pays scant attention to the people directly caught up in these economic events. These trends were inexorably leading to an ominous deterioration of sub-Saharan Africa's scarce human capital, which can be replaced only at great cost. They were setting the stage for an accelerated spiral of decline in the continent's future development. (Quoted in Brown, 1995, p. 266)

Public sector workers were not immune and in many cases suffered from reduced pay and greater insecurity. This was the result of reduced government income, but also conditionality requirements from the World Bank and the IMF. The result was that, from the early 1980 s to the early 1990 s, the number of people employed by central government in Sub-Saharan Africa fell from 1.8 per cent to 1.1 per cent of the population, and the average government wage also fell from 6.1 times per capita GDP to 4.8 times (SchiavoCampo, de Tommaso and Mukherjee, 1997). In Anglophone Africa, public sector wages declined by as much as 80 per cent in real terms between the early1970s and the early 1980s (Ayee, 2005).

Uganda provides one of the most vivid examples, with pay for civil servants in the late 1980 s falling to only $\$ 10$ a month (Kiragu and Mukandala, 2005). A reform programme was launched in 1993 which halved the number of public servants through the reduction in ghost workers, a voluntary redundancy scheme and a selective freeze on recruitment. Although this was coupled with significant salary increases in the early 1990 s, the objective of a minimum living wage for Ugandan civil servants is far from being realized according to Mark Robinson, who concludes that:

Failure to make progress on pay reform for the vast majority of public servants contributes to declining motivation. Large differentials between administrative grades and top civil servants, along with special treatment for senior officials in the political bureaucracy and semiautonomous bodies like the URA, fuel resentment, undermine morale and provide a stimulus to corruption. The lack of incentives for public servants who have to cope with continuous reform initiatives and future uncertainty further runs counter to a key objective of the reform programme as set out by the 1991 presidential commission, namely the creation of a committed, responsible and results-oriented civil service, which would be better paid, more efficient, and have more effective staff. (Robinson, 2006)

Similarly, in 2002, Charles Byaruhanga could conclude that in Uganda:

Public sector pay has improved over the last decade though pay reform remains on the public sector institutional agenda. Pay for managerial, technical and professional civil service remains un-competitive, leading to difficulties in recruiting and retaining competent staff and also negatively impacting on public service delivery.

A more recent example of the effect of economic collapse on the salaries of public officials is Liberia, where salaries of civil servants fell to a range of only $\$ 30$ to $\$ 55$ per month (Kumar and Brar, 2008). Many experienced and qualified staff left the public service and the country. This loss of human resources contributed to the major breakdown of government systems.

The poor pay and conditions in the African public sector has been matched by the 
attraction of working in developed countries: 'Approximately 20,000 skilled workers leave Africa each year. The World Bank's estimate of the share of Africa's skilled workers with a tertiary education who emigrate is more than 15 per cent, higher than any other region' (Bond, 2006, p. 89). In these circumstances, the loss of key public sector financial managers has led to the greater use of foreign consultants. However, the success of especially large-scale reforms like IFMIS and MTEF is dependent on the existence of local experts who are able to engage critically with these international consultants. The loss of this local knowledge and experience meant the strengths and challenges of existing systems are not adequately understood and so the linkages between the new and existing systems are not optimized. In addition, the absence of such local expertise has meant that the sustainability of the reforms has not been possible.

\section{USE AND CRITICISMS OF THE REFORMS}

Despite the great claims made for the benefits of financial management reforms, the outcomes have often been disappointing. Many of the presumed benefits have been based more on theory and what should happen after the reforms have worked their way through the system. These reforms continue to be heavily supported by the international financial institutions and the country aid agencies. However, the 'actual level of success from their implementation has been surprisingly low. In many cases, where results have not lived up to expectations, this is not laid at the door of the "reforms" but rather at the door of the governments who have not gone far enough, or have backed off under pressure from "vested interests"' (Rosskam, 2006, p.ix). And the Danish Institute for International Studies says: 'blue-print approaches and fixed ideas about what constitutes a governance agenda can have dangerous consequences, and they demonstrate how pragmatic initiatives that do not necessarily reflect widespread ideas about "good governance" can bring about positive results' (http://www.diis.dk/sw66424.asp).

This need for a fundamental review of actual progress is supported by a former senior official of the World Bank, who said that:

The introduction of the MTEF concept and its early application are now some 15 years old, and the time for a candid and fact-based assessment is long overdue. Given the hype the MTEF has enjoyed, its rapid expansion in the last decade, and the disregard of some fundamental considerations of institutions and capacity, a little extra emphasis in the interest of understanding the actual issues is timely. (Schiavo-Campo, 2008)

In 2005 one of the authors of this chapter (Wynne, 2005) reviewed the progress with implementation of MTEF and IFMIS reforms in Ghana, Tanzania and Uganda.

The introduction of the MTEF in Ghana appeared to have been an example of consultants and aid agencies encouraging the adoption of multi-year budgeting based on the limited experience in similar countries. This reform was thought to have been overambitious, as in recent years Ghana had been struggling to implement its agreed annual budget.

The Tanzanian MTEF was considered to be one of the most comprehensive in Africa (Le Houerou and Taliercio, 2002). But its success, as measured against the support for fiscal balance and in promoting the reallocation of financial resources to finance poverty 
eradication programmes, appears to have been rather limited. Although spending in the priority poverty reducing areas seemed to have increased more than in other areas of the government's budget, this increase had been relatively modest.

The Ugandan MTEF was considered to be one of the best examples of the success of the initiative in Africa. The introduction of an MTEF was certainly associated with improved macroeconomic stability, although it is difficult to prove the causal relationship. However, this reform has not focused on shifting funds towards poverty reduction activities. All areas of expenditure benefited equally from increased absolute funding during the implementation of the MTEF. Education, which is one of the priority areas, grew marginally, but its share in the overall government expenditure remained unchanged over the period of five years during which the MTEF was implemented.

In terms of the IFMIS, this had not been successful in Ghana. Agreed in 1997, it was re-launched in 2004, and a new project was started in mid-2010 to try to provide an integrated financial system for the central government.

In Tanzania, the IFMIS has been successful in terms of providing timely financial management information and improving commitment control. However, this only covered central government units in Dar es Salaam; budgetary information had to be reentered once the annual budget was agreed; and the system was not linked to either the payroll or the revenue system. Despite these limitations, several other African countries have adopted the same approach as the Tanzanian government, including Malawi and The Gambia.

Uganda was at the pilot stage of a large and complex project to provide an integrated computer platform and financial system for the whole of central and at least the larger local governments. The project had suffered only limited delays relative to the original timetable. However, the risks are still considered to be significant.

This study of the implementation of MTEF- and IFMIS-type reforms in these three African countries (Wynne, 2005) concluded that:

given the past record of limited success with the implementation of MTEFs, IFMISs and other major reforms, the need for such approaches and the evidence of their successful implementation in other countries should be rigorously reviewed. The traditional public sector concerns with regularity and probity will, if anything, become more important when major reform initiatives are being considered. Small-scale investment in basic internal financial controls may often bring greater returns than large investment in innovative reforms with their associated significant risks of failure.

MTEFs and IFMISs are considered, at least by the international financial institutions to be core public financial management reforms for many developing countries. Their level of success, however, has been relatively modest and many of the assumed benefits have not necessarily been achieved. As a result, scarce resources and expertise may have been wasted on initiatives whose success in practice had not necessarily been adequately tested. (Wynne 2005, p. 32)

Both the MTEF and the IFMIS are large, complex and strategic reforms and so are high-risk projects that have actually suffered high levels of failure. Thus, for example, World Bank staff have estimated that only 6 per cent of the IFMISs they funded were highly likely to be sustainable (Dorotinsky, 2003). However, it is the strategic nature of these reforms which can be attractive to those who believe that the public sector in the Global South requires fundamental change.

A former IMF and World Bank official admitted that: 
A first glimmer of recognition of these problems [with the MTEF] appeared at the World Bank's 'PREM Week' meeting of late 2000, when it was noted, among other things, that if a country cannot put together a sensible annual budget and execute it in minimally acceptable fashion it is very unlikely to have any use for a medium-term expenditure framework. One panellist (Alister Moon) gave a long list of preconditions for introducing an MTEF, including macroeconomic stability; revenue predictability; early political commitment; core capacity of the finance ministry and central agencies; supportive donor behaviour; capacity to enforce a hard budget constraint at the ministry level; executive commitment to having a transparent budget process; and capacity in sector policy analysis. (Schiavo-Campo, 2008, p. 5)

Despite these warnings of implementation difficulties, and the calls for country-led reforms, the international financial institutions and aid agencies still have a dominant role in the direction of public financial management, and MTEFs and IFMISs are still being heavily promoted as the way to improve and to modernize public sector financial management across Africa.

\subsection{Sustainability of the Systems - Expensive General System Failures}

There were great expectations for the MTEF and IFMIS reforms, but they have often failed in practice. The results of nearly 15 years of experience of introducing the MTEF across the Global South have been summarized by a former senior IMF and World Bank official as:

- virtually no evidence of improved macroeconomic balance

- some limited evidence of reallocation to priority subsectors

- no evidence of a link to greater budgetary predictability

- no evidence of efficiency gains in spending.

This is what the donors and the developing and middle-income countries have got in return for the billions of aid dollars, mountains of red tape, heavy burdens on local government staff, and literally centuries of full-time-equivalent technical experts. (Schiavo-Campo, 2008, p. 6)

And 'there is mounting skepticism of all MTEF concepts - seen as exhausting and expensive initiatives pushed by donors, and carried out as supply-driven self-propelled exercises conducted mainly by external consultants' (Schiavo-Campo, 2008, p. 7).

In addition, Allen Schick, a frequent presenter at World Bank public financial management events, has commented: 'Medium Term Expenditure Frameworks (MTEFs) have not proven a panacea to the challenges of budget planning, preparation and management in most countries. A possible epitaph for MTEF-type reforms would read "Died of many causes, each of which was sufficient"' (Schick, 2008).

These problems have been known for years. In a major study for the World Bank, Le Houerou and Taliercio (2002) came to the following conclusions on the progress with the introduction of the MTEF across Africa:

The limited quantitative evidence shows, thus far, that MTEFs are not yet unambiguously associated with their objectives ... In terms of macroeconomic balance, with the possible exception of Uganda, there is no evidence that MTEFs have made a significant impact. In terms of resource allocation, there is some limited and qualified evidence to suggest that MTEFs are linked to reallocations to a subset of priority sectors. With respect to budgetary predictability 
and consistency, there is no support for the assumption that MTEFs are associated with greater discipline and less deviation. At best, then, these cases present a mixed picture. (Le Houerou and Taliercio, 2002, p. 24)

At a major World Bank seminar to re-assess its public financial supported reforms, including a review of its experience with the MTEF, one official commented: 'The realization of the magnitude of wasted resources and dashed expectations is sobering' (Schiavo-Campo, 2008).

Another of the presenters at this event asked: 'Have certain donor-led PFM [public financial management] initiatives complicated the PFM reform landscape in countries, eg MTEF?', and a World Bank staff member said that MTEFs had become a reputational risk to the Bank. It is hoped that these reviews will lead to greater changes in practice and advice to governments. It seemed clear that the World Bank needs to put more effort into listening to local public sector financial officials, building on their expertise and understanding of the local environment to ensure that local public sector financial management reform programmes are more successful in future.

Large-scale electronic information system implementations are notoriously risky. The hope in respect of governments of the Global South was that they could benefit from the lessons of failed implementations in the developed world. In practice, this seems not to have been the case. The following three quotations indicate the huge gulf between the hype and the reality of IT reforms:

In the emerging knowledge-based economy of the 21 st century, information and communications technology will likely assume an importance that dwarfs other types of infrastructure. This shift offers Africa a chance to leapfrog intermediate stages of development by avoiding costly investments in time, resources, and the generation and use of knowledge. Africa has a chance to benefit not only as a consumer in the new knowledge economy, but also as a producer. It cannot afford to miss this opportunity. (World Bank, 2000, p. 153)

E-government is difficult to implement, hard to manage and often fails. (Heeks, 2006, p. 10)

Survey and poll results produce the following working estimates about e-government initiatives in developing/transitional countries:

- $35 \%$ are total failures

- $50 \%$ are partial failures

- $15 \%$ are successes. (eGov for Development, 2007)

IFMIS in particular and IT in general have been promoted as providing the key answers to improving the quality and efficiency of a modern public sector. However, the reality has been a series of failed projects and, in many cases, the wastage of millions of dollars which are desperately needed for investment in many other areas of the public sector.

In Ghana, for example, an IFMIS was launched in 1997 by Vice-President Mills. $\mathrm{He}$ argued that the IFMIS would:

not only facilitate budget execution, accounting and financial reporting but will also place responsibility on the Ministers to monitor and account for resource use ... the policies we formulate, the programmes we implement, the resources we use, must all be accounted for in 
terms of the extent to which they help us improve our living standards. (PUFMARP newsletter, September 1997, pp.4-5, quoted in Fyson, 2009)

However, nearly a decade later, in May 2006, the deputy controller and accountant general noted that: 'there has as yet not been one Cedi [local currency] benefit from it. I have not used [IFMIS] to generate one report yet' (quoted in Fyson, 2009).

This experience has also been replicated in industrial countries. An important book (Gauld, Goldfinch and Dale 2006) reviews a number of IT case studies in Australia, Britain, New Zealand and the United States. As a result, the authors reach the conclusion that IT is a dangerous enthusiasm. In contrast they argue that pessimism, or at least the expectation of failure, should be the guiding principle.

These conclusions appear to be even more relevant and important in Africa, where the experience has, if anything, been worse in terms of the risk of IT failure, as the following quotations demonstrate: 'the evidence does all point in one direction: towards high rates of e-government project failure in Africa' (Heeks, 2002, p. 11); 'information systems fail or under perform more often than they succeed in the public sector in Africa' (Peterson, 1998, p. 38); 'the success rate of introduced information technology systems in African state agencies has been distressingly low' (Berman and Tettey, 2001, p. 2).

One of the reasons for this high failure rate is that the economics of IT investment in Africa is different from that found in industrial countries. In Africa, labour is relatively cheap, IT hardware and skills are not available locally, and transport costs make IT more expensive to purchase and to maintain. Average public sector wage costs in Africa can be one-tenth or less of those in industrial countries. Average IT costs, in contrast, may be two to three times higher. E-governance and automation using modern IT technology therefore result in replacing cheap civil servants with costly IT (Heeks, 2002).

In late 2003, Bill Dorotinsky provided a useful overview of the World Bank's experience of providing over $\$ 1$ billion to finance IFMIS projects over 17 years. The average time for completion of each project was over nine years for African projects, and the average cost of each of the 34 projects worldwide was $\$ 12.3$ million (Dorotinsky, 2003).

If success is defined on the basis of being on budget, on time and delivered as planned, then only 21 per cent of these projects were successful. An even gloomier view was provided by assessments of the same projects by the World Bank staff. A quarter of the projects were considered unsustainable, 69 per cent likely to be sustainable and only 6 per cent highly likely to be sustainable, and this figure was lower for Africa than other regions (Dorotinsky, 2003).

Dorotinsky stated that the general lesson from the World Bank's experience was the requirement to have clear political commitment and ownership by the borrowing country. He also pointed out that such schemes were generally less successful in poorer countries and highlighted the following additional risks:

- Lack of capacity

- Lack of government commitment

- Too many project components

- Opposition by staff and line ministries (Dorotinsky, 2003).

In 2005 the IMF published a working paper which investigates the reason for the serious delays and frequent failure to implement and sustain IFMIS reforms in governments of 
the Global South (Diamond and Khemani, 2005). This paper concludes that an IFMIS should be implemented as part of a wider set of public financial management reforms. The IFMIS will require clear government commitment, support and significant resources. It should also be phased over a number of years when current and interim arrangements will still be required. Even if these recommendations are implemented, a government implementing an IFMIS can expect 'a long implementation path, and one that involves significant challenges. It will be a complex learning process for all concerned. A number of difficulties are likely to be encountered en route' (Diamond and Khemani, 2005, p. 27).

\section{SUGGESTIONS FOR A WAY FORWARD}

In this section we examine possible ways to assist governments of the Global South in their efforts to improve their use of information systems and accounting technologies, suggesting that local experts should take control to rebuild public sector financial management.

The international financial institutions and aid agencies may adopt suitable strategic objectives, but these are not necessarily properly implemented. They are used only as slogans and are not seriously used as a guide to action. Thus the following ideas have been correctly promoted in recent years to guide public financial management reform, but have not been delivered in practice:

- country ownership;

- getting the basics right;

- sequencing of reform.

If we accept the arguments of the previous sections, then public financial management was relatively successful, but became degraded in many governments of the Global South as a result of events beyond the control of these governments. In these circumstances, what these countries need is a rebuilding and refinement of their public financial management systems rather than the root-and-branch reform suggested by such megareforms as the MTEF and IFMIS. This should be led by the countries concerned and, specifically, their financial managers, who are the only experts on these systems.

\subsection{Country Ownership}

Country ownership has been widely accepted and considered vital for the success of large-scale public financial management reforms, especially since the OECD's Paris Declaration was adopted by over 100 ministers, heads of agencies and other senior officials in 2005. This agreement committed the donors to 'Respect partner country leadership and help strengthen their capacity to exercise it' (OECD, 2005).

The report to the follow-up meeting in Accra, Ghana in October 2008 reinforced this view, noting that:

Country ownership and leadership are critical to success. Even when external pressures or internal crisis are the main triggers PFM reforms, the starting point for real reform must be a 
country-owned response to such pressure in the form of a program of reform and a country-owned structure for managing the reform process. (Working Party on Aid Effectiveness, 2008, p. 17)

This report also noted that:

The literature on PFM is replete with stories of failed reforms that were driven by donors rather than led by the country; such reforms may initially appear to be successful, but they are unlikely to be sustained and, in the worst cases, may be reversed after the withdrawal of donor support. (Working Party on Aid Effectiveness, 2008, pp. 18-19)

Despite these harsh warnings, the Declaration claims that it is the responsibility of each government in the Global South 'to take leadership of its development processes' (Working Party on Aid Effectiveness, 2008, p.4), rather than the international financial institutions and aid agencies, as the most powerful partners, having the responsibility to ensure that governments of the Global South are allowed to control their own destinies.

In practice the international financial institutions and aid agencies (led by the IMF and the World Bank) maintain close control over the public financial reforms. Most public financial management projects which are funded by World Bank loans will have originated from a World Bank report. In addition, many aid projects are also micromanaged by the aid agencies; for example, all contracts let under World Bank funded projects for public financial management reform have to be screened by World Bank officials to receive a 'no objection' clearance before the contract can be awarded. In addition, the contracts may be managed by independent agencies and periodically reviewed by World Bank officials.

As a former senior official of the IMF and World Bank said at an IMF seminar in October 2008: 'There is little or no country ownership. MTEF is often pushed on to reluctant countries by donor agencies.' Despite this approach, the World Bank, for example, still has a tendency to blame the relevant country rather than the particular tools it has promoted. So in 1998 the World Bank said that 'advocates continue to suggest that the failure of these performance-orientated tools [an aspect of the MTEF] or techniques have been in implementation rather than in concept' (World Bank, 1998, p. 16). Over a decade later at a World Bank seminar Allen Schick was still claiming that 'the widespread failure of MTEF has been due to the way it has been implemented, not because of a design flaw' (Schick, 2008).

Foucault argued that political rationalities prescribe solutions and ways to achieve these prescriptions while at the same time presenting these solutions as the truth. The prescription of ways and means does not necessarily mean that political rationalities would be achieved in practice. Instead, political rationalities are congenitally failing, with their implementation the commencement of the search for ever new ways of governing a sphere (Miller and Rose, 1990; Rose and Miller, 1992).

The World Bank employs public financial management advisors in most aid-dependent countries, directly provides or supports a range of training initiatives for public financial management officials, and produces a range of publications relating to particular countries or of more general interest. Co-operative bodies for public financial management officials, for example AFROSAI-E (for auditors general), CABRI (for budget officials) and ESAAG (for accountants general), are dependent on the aid agencies for support and for the provision of international speakers for their events. All these activities tend 
to increase the influence of the international financial institutions and the aid agencies. In addition, these bodies are able to recruit leading public sector financial managers and officials. For example, the former federal minister of finance of Nigeria worked for the World Bank before and after her term in office; the current president of Liberia worked for the World Bank; the head of public sector financial reform in Sierra Leone went on to work for the World Bank; and the auditor general of Uganda had a spell working for the PEFA Secretariat before returning to Uganda.

The standard approach to evaluating the quality of public financial management in the Global South is now the PEFA framework. These have been undertaken in over 100 countries, with particularly high coverage in Sub-Saharan Africa (PEFA Secretariat at the 2009 International Consortium of Governmental Financial Management Miami Conference). However, very few of these assessments were undertaken with the active involvement of the public sector officials of the country under review. Most are led by the World Bank or the EU and involve international consultants. The auditor general of Uganda did undertake a PEFA-type review in 2007, but this was criticized by the PEFA Secretariat, as it was uncertain whether the donors would accept it as part of their fiduciary assessments.

\subsection{Getting the Basics Right}

Public financial management reform should clearly be based on firm foundations; we have to 'get the basics right', to use Allen Schick's often repeated (and then ignored) phrase. Specifically, Schick has called for the need to 'operate a reliable accounting system before installing an integrated financial management system' (World Bank, 1998) and 'focusing on the credibility of the annual budget before introducing a medium-term perspective to budget planning' (Schick, 2008).

Despite these wise words, governments have been encouraged to adopt the MTEF and IFMIS before basic internal financial controls have been brought up to an adequate standard. As an IMF working paper noted, 'MTEFs have sometimes been introduced prematurely, in the sense that annual budget outcomes and monitoring mechanisms were still quite primitive, resulting in outer-year scenarios that were inconsistent with actual budget outcomes and/or the macroeconomic framework' (Lienert and Feridoun, 2001).

Schiavo-Campo (2008, p.7) warned against MTEF and IFMIS being seen as the basic approaches to financial management for all governments, national and local: 'The "reform" momentum is still at work, however. Especially troublesome is the notion of extending the MTEF to general government, requiring sub-national entities to go through the exercise - as currently envisaged in some countries, e.g., Tanzania.'

This is also the case in Nigeria, where both the World Bank and the Department for International Development (UK) are supporting public sector reforms in a number of state governments. The MTEF is seen as a key part of these reforms (at least by the donors), although PEFA indicators for basic internal financial controls are poor.

Somalia is well known for not having had a functioning national government for nearly two decades. Despite this, a World Bank mission to Somalia in late 2007 led to the recommendation to introduce an IFMIS. This is despite Schick's recommendation to ensure that manual systems are working well before an IFMIS is introduced. Similarly, 
donor-supported IFMISs have been implemented in several other post-conflict countries, including Liberia (Kumar and Brar, 2008), Sierra Leone and Southern Sudan.

\subsection{Sequencing of Reform}

Sequencing of public sector financial reforms is clearly important and may be another way of ensuring that basic internal financial controls are refined before wide-ranging mega-reforms such as the MTEF and IMFIS are implemented. But this approach may also be based on the assumption that donors know what is needed and it is just a question of moving there in small, easy steps. Thus the Department for International Development (UK) describes this type of approach as follows:

The platform approach aims to implement a package of measures or activities designed to achieve increasing levels ('platforms') of PFMA competence over a manageable timeframe. Each platform establishes a clear basis for launching to the next, based on the premise that a certain level of PFMA competence is required to enable further progress to take place. (DfID, 2005, p. 1)

This approach assumes that donors know what is needed, that the main attributes of sound public financial management are well understood and that all countries should achieve this common goal. It is just a question of determining where on the development ladder a particular country finds itself to indicate what the next steps should be. However, reality is more complex. There is a variety of different approaches to public financial management, and each country and organization has, to a greater or lesser extent, developed its own approach. 'The rush for reforms, especially when driven from outside, has often wreaked havoc in vital institutions that societies had created either to foster national unity, defend disadvantaged groups and regions or support national investments' (Larbi, 2006, p. 3).

We have to start from a clear understanding of the particular priorities, demands, history and culture of each country, elements which local public financial managers are best able to understand. We then have to consider carefully how existing systems may be rebuilt, improved and refined in the light of local experience, informed, as appropriate, by the lessons and experience of other countries.

Some experiences with implementation suggest that, to reduce the risk involved in developing an IFMIS, it may be preferable for the system to be implemented in stages with, for example, the implementation of a computerized payments and budget monitoring system in the ministry of finance as a first stage and the extension to line ministries as the second stage, and only after the system has proved to be working effectively should its use by regional and/or local government be considered. An incremental approach is suggested by Peterson (2007):

Both the Ethiopian and Tanzania experience with automating financial systems demonstrate the value of a modular approach and the need to selectively not comprehensively address core deficiencies of financial control - fixing the hole(s) in the whole. They both involved extensive customization to meet user requirements. They both put into question the need for 'high end' commercial off-the-shelf systems which are expensive, complex, difficult to customize and have features which have little or no use for the current or foreseeable needs of a government. (Peterson, 2007, p.40) 


\section{CONCLUSIONS}

The economies of many countries in the Global South went into deep decline from the mid- to late 1970s with the associated rise in government debt. This was largely due to external events: the increased price of oil, increased interest rates and declining prices for their exports. These were events which governments had little or no control over and for which they were not responsible. However, it did mean that their income was severely curtailed. As a result, they were encouraged by the IMF, World Bank and aid agencies to restructure their economies, corporatize and/or privatize key sectors of the economy, adopt Western accounting procedures and systems, reduce the number of their public servants and in many cases significantly reduce their level of pay. This clearly had a detrimental effect on the quality of public services, including financial management and overall governance.

Of course, if the developing countries had solved all of their own problems better, if they had more honest governments, less influential special interests, more efficient firms, better educated workers - if, in fact, they did not suffer from all the afflictions of being poor - they could have managed this unfair and dysfunctional globalisation better. (Stiglitz, 2006, p. 58)

However, these events have given the World Bank and aid agencies the power, through aid conditionality, to influence significantly the public sector financial management reforms which were introduced. This has often been through the use of, usually European, consultants paid significantly more than the financial managers they are retained to advise.

Public sector financial managers, far from being the cause of this decline, have in many cases struggled to try to maintain standards whilst suffering redundancies, forced retirements and dramatic cuts in their living standards. In addition, their morale has been undermined.

Global solutions do not necessarily satisfy local needs. The evidence of the previous sections demonstrate the failure of systems and procedures imported and implemented by 'experts' who may not appreciate the local history, society or culture of the countries in which they are sent to operate. The great expectations of the 'solutions' often result in expensive failures.

Costly failures have demonstrated that - as any other institutional reform - successful introduction of a programmatic MTEF takes years of persistent efforts consistent with capacity, resources, awareness, incentives, and institutional realities. The two ingredients of the approach are therefore gradualism and selectivity, and the main conditions of success are simplicity and communication. If prematurely introduced or badly implemented, a formal and detailed programmatic MTEF causes enormous waste, frustration, and illusion - for trivial or non-existent benefits. The same is true of the informatics infrastructure for public financial management. (Schiavo-Campo, 2008, p. 26)

The authors argue that it is better to build on and enhance existing public financial management capacity, to nourish it and facilitate its development. The local officials are the international experts for the systems they are responsible for managing. For any systems the experts are the local officials. No consultant from outside the sector or country can know or understand the system as well as the public sector officials who 
have been managing the system for years, often in very difficult circumstances. These arose as a result of external events beyond their control or that of their governments. All public financial management reforms should be led by the relevant officials and should be subject to informed local political support.

Complex systems and reforms are always more risky than simple approaches. The authors believe that it is better to ensure that proposed reforms are kept as simple as possible.

'International best practice' has to be adapted to make it fit local conditions: international best practice is never the complete answer.

The authors would also argue for the importance of making sure that actual international best practice is being adopted and checking to ensure that the particular aspects really have been tried and tested and have been proved to be successful. Multi-year budget frameworks and programme budgeting may be good ideas, but they have been difficult to implement in practice. The UK tried for 30 years until 1997 to implement a three-year budget framework, and it is not clear that the current arrangements will survive the recent international financial turmoil. France only implemented its current approach to programme budgeting from 2006 and is only implementing a three-year budget framework with effect from 2008. The US government does not have an MTEF.

There are many other examples of reforms which were once heavily promoted by aid agencies and international consultants which time then showed were either mistaken or carried significant additional associated costs.

It would appear that the World Bank and the IMF are now slowly revising their support for mega-reforms such as the MTEF and IFMIS. In 2008 both organizations held significant seminars reviewing the evidence for the success (or more commonly failure) of such reforms.

However, there is still a long way to go. We need to gain widespread recognition that the governance and financial management problems suffered by many countries arose from global events over which they and their governments had little or no control. The international financial institutions and the donor agencies need to ensure that they use their financial power judiciously to enable public financial managers to take real leadership of their reform agenda.

The change agenda arising from the world recession and the election of Barack Obama as the US president on a programme of change should help this process. We need a move away from mega-reforms such as the MTEF and IFMIS. Public financial managers need to be provided with the political support and necessary resources to implement basic tried and tested reforms.

The World Bank says it is working for a world free of poverty. However, its prescriptions for public sector financial management are unlikely to achieve this ideal. The far more modest aims of the Millennium Development Goals are also now, as a consequence of the global recession, not likely to be achieved. The private sector free market approach of neoliberal and NPM reforms has failed. We need to change direction and build poverty reduction strategies on the firm foundations of redistributing resources from the richer to the poorer sectors of society through the use of progressive taxation and public services provided free at the point of use. 


\section{REFERENCES}

Awio, G., S. Lawrence and D. Northcott (2007). Community-led initiatives: reforms for better accountability? Journal of Accounting and Organizational Change, 3(3), pp. 209-26.

Ayee, J.R.A. (2005). Public Sector Management in Africa. Tunis: African Development Bank.

Ayeni, V. (2002). Public Sector Reform in Developing Countries: A Handbook of Commonwealth Experiences. London: Commonwealth Secretariat.

Berman, B.J., and W.J. Tettey (2001). African states, bureaucratic culture and computer fixes. Public Administration and Development, 21.

Bond, P. (2006). Looting Africa: The Economics of Exploitation. London: Zed Books.

Brown, Michael Barratt (1995). Africa's Choices: After Thirty Years of the World Bank. London: Penguin Books.

Byaruhanga, Charles (2002). Poverty Reduction and Public Sector Reform in Uganda: The Roles of Institutions in Past Experience and Challenges for the Way Forward. Oxford: Consulting Africa.

Christian Aid (2003). The Trading Game: How Trade Works. Oxford: Oxfam.

Clark, T., and A. Dilnot (2002). Measuring the UK Fiscal Stance since the Second World War, Briefing Note no. 26. London: Institute for Fiscal Studies.

DfID (2005). A Platform Approach to Improving Public Financial Management, Briefing. London: DfID.

Diamond, Jack, and Pokar Khemani (2005). Introducing financial management information systems in developing countries. IMF Working Paper, Fiscal Affairs Department, http://www.imf.org/external/pubs/ $\mathrm{ft} / \mathrm{wp} / 2005 / \mathrm{wp} 05196 . \mathrm{pdf}$.

Dorotinsky, Bill (2003). Implementing Financial Management Information System Projects: The World Bank Experience Preliminary Results, http://wwwl.worldbank.org/publicsector/egov/ReinventingGovWorkshop/ dorotinsky.ppt.

Duménil, G., and D. Lévy (2005). Costs and benefits of neoliberalism: a class analysis. In Financialization and the World Economy, ed. G. Epstein. Cheltenham, UK and Northampton, MA, USA: Edward Elgar. (Updated version of the paper originally published as: Duménil, G., and D. Lévy (2001). Review of International Political Economy, 8(4), pp. 578-607, http://www.jourdan.ens.fr/levy/dle2005g.htm, accessed 29 October 2008.)

eGov for Development (2007). http://www.egov4dev.org/, accessed 24 August 2007.

FAO (2005). The State of Agricultural Commodity Markets 2004. Rome: UN Food and Agriculture Organization.

Fyson, Sara (2009). Sending in the consultants: development agencies, the private sector and the reform of public finance in low-income countries. International Journal of Public Policy, 4(3-4), pp. $314-43$.

Gauld, Robin, and Shaun Goldfinch with Tony Dale (2006). Dangerous Enthusiasms: E-government, Computer Failure and Information System Development. Dunedin: Otago University Press.

Hashim, Ali, and Bill Allan (2001). Treasury Reference Model, http://www1.worldbank.org/publicsector/pe/ trm.pdf.

Heeks, Richard (2002). eGovernment in Africa: Promise and Practice, Paper 13. Manchester: IDPM, University of Manchester.

Heeks, Richard (2006). Implementing and Managing eGovernment. London: Sage.

ILO/JASPA (1991). Africa Employment Report 1990. Addis Ababa: ILO/JASPA.

Kiragu, Kithinji, and Rwekaza S. Mukandala (2005). Politics and Tactics in Public Sector Reforms: The Dynamics of Public Service Pay in Africa. Dar es Salaam: Dar es Salaam University Press.

Kumar, S.M., and P.P.S. Brar (2008). Transition to IFMIS: the Liberian experience. Paper presented at the International Conference of the Controller General of Accounts of India, on Public Financial Management for Improving Programme Delivery: Issues and Challenges, New Delhi, 20-22 October.

Larbi, G.A. (2006). Applying the new public management in developing countries. In Public Sector Reform in Developing Countries: Capacity Challenges to Improve Service, ed. Y. Bangura and G.A. Larbi. New York: United Nations Research Institute for Public Development/Palgrave.

Le Houerou, P., and R. Taliercio (2002). Medium term expenditure frameworks: from concept to practice: preliminary lessons from Africa. Africa Region Working Paper Series no. 28, http://www.worldbank.org/ afr/wps/wp28.pdf.

Leys, Colin (1996). The Rise and Fall of Development Theory. Oxford: James Currey.

Lienert, I., and S. Feridoun (2001). Systemic weaknesses of budget management in Anglophone Africa. IMF Working Paper 01/211.

Miller, P., and N. Rose (1990). Governing economic life. Economy and Society, 19(1), pp. 1-31.

National Audit Office (2006). Central Government's Use of Consultants, Value for Money Report. London: NAO, http://www.nao.org.uk/pn/06-07/0607128.htm.

OECD (2005). Paris Declaration on Aid Effectiveness. Paris: OECD. 
Office of Management and Budget (2007). Historical Tables: Budget of the United States Government: Fiscal Year 2008, p. 126. Washington, DC: Executive Office of the President of the United States, http://www. whitehouse.gov/omb/budget/fy2007/pdf/hist.pdf, accessed 17 September 2008.

Olson, O., J. Guthrie and C. Humphrey (eds) (1998). Global Warning: Debating International Developments in New Public Financial Management. Oslo: Cappel Akademisk Forlag.

Peterson, S.B. (1998). Saints, demons, wizards and systems: why information technology reforms fail or underperform in public bureaucracies in Africa. Public Administration and Development, 18(1).

Peterson, Stephen (2007). Imperfect systems: IFMISs in Africa. Harvard University.

Robinson, M. (2006). The political economy of governance reforms in Uganda. IDS Discussion Paper 386.

Rose, N., and P. Miller (1992). Political power beyond the state: problematics of government. British Journal of Sociology, 43(2), pp. 173-205.

Rosskam, Ellen (ed.) (2006). Winners or Losers? Liberalising Public Services. Geneva: ILO.

Schiavo-Campo, Salvatore (2008). Of mountains and molehills: 'the' medium-term expenditure framework. Paper presented at the Conference on Sustainability and Efficiency in Managing Public Expenditures, organized by the East-West Center and Korea Development Institute, Honolulu, HI, 24-25 July, http://papers. ssrn.com/sol3/papers.cfm?abstract_id=1169783, accessed 20 September 2008.

Schiavo-Campo, S., G. de Tommaso and A. Mukherjee (1997). An International Statistical Survey of Government Employment and Wages. Washington, DC: World Bank.

Schick, Allen (2008). Sequencing issues in PFM reform. World Bank PFM Seminar, 21 March, blog-pfm.imf. org/pfmblog/files/thoughts_shared_by_prof_allen_schick_at_the_workshop_on_March_21st.doc.

Situmbeko, Lishala C., and Jack Jones Zulu (2004). Zambia: Condemned to Debt. London: World Development Movement, http://www.africafocus.org/docs04/zam0406.php.

Stiglitz, J. (2006). Making Globalisation Work. London: Allen Lane.

UNCTAD (2004). Debt Sustainability: Oasis or Mirage. New York and Geneva: United Nations.

Working Party on Aid Effectiveness, Joint Venture on Public Financial Management (2008). Report on the Use of Country Systems in Public Financial Management. Paris: OECD.

World Bank (1998). Public Expenditure Management Handbook. Washington, DC: World Bank, http://www1. worldbank.org/publicsector/pe/handbook/pem98.pdf.

World Bank (2000). Can Africa Reclaim the 21st Century? Washington, DC: World Bank.

World Bank (2005). The Medium-Term Expenditure Framework: The Challenges of Budget Integration in SSA countries, Africa Region Working Paper Series no. 82, April. Washington, DC: World Bank.

Wynne, Andy (2005). Public Financial Management Reforms in Developing Countries: Lessons of Experience from Ghana, Tanzania and Uganda, Working Paper no. 7. Harare: African Capacity Building Foundation, http://www.acbf-pact.org/knowledge/documents/Working\%20Paper\%207\%20on \%20Financial\%20Manage ment-Final.pdf. 